\title{
Combining climatic and geo-hydrological preconditions as a method to determine world potential for aquifer thermal energy storage
}

\author{
Martin Bloemendal ${ }^{\mathrm{a}, \mathrm{b}, *}$, Theo Olsthoorn ${ }^{\mathrm{a}, \mathrm{c}}$, Frans van de Ven ${ }^{\mathrm{a}, \mathrm{d}}$ \\ a Department of water management, Delft University of Technology, Delft, The Netherlands \\ ${ }^{\mathrm{b}}$ KWR, Water cycle Research Institute, Nieuwegein, The Netherlands \\ ' Waternet, Public Water Cycle Company Amsterdam, The Netherlands \\ d Deltares, Water Research Institute, Utrecht, The Netherlands
}

\section{H I G H L I G H T S}

- Geo-hydrological and climatic properties are converted to ATES suitability.

- The regions are determined where the potential for ATES is favorable.

- Hot-spots of high ATES potential were identified by including urbanization.

- Shown is where demand for ATES is likely to exceed available space in the subsurface.
G R A P H I C A L A B S T R A C T
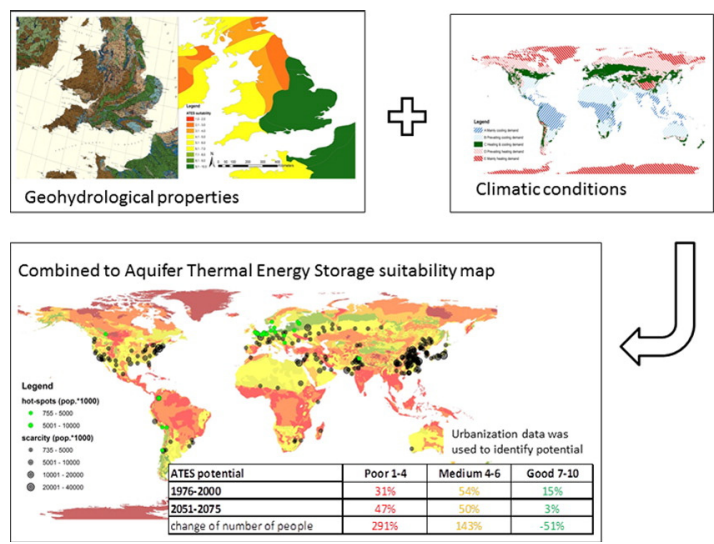

A B S T R A C T

A heat pump combined with Aquifer Thermal Energy Storage (ATES) is proven technology to economically and sustainably provide space heating and cooling. The two most important preconditions for the applicability of ATES are favorable climatic conditions and the availability of a suitable aquifer. This paper shows how these two preconditions can be combined to identify where in the world ATES potential is present, or will become present as a consequence of climate change. Countries and regions are identified where regulation and stimulation measures may increase application of ATES technologies and thus help reduce $\mathrm{CO}_{2}$-emissions.

Two types of data determine ATES suitability, and their combination with a 3rd identifies potential hot-spots in the world: 1) geo-hydrological conditions, 2) current and projected climate classification and 3) urbanization. Our method combines the data into an ATES-suitability score as explained in this paper. On the one hand the results confirm the suitability for ATES where it is already applied and on the other they identify places where the technology is or will become suitable. About $15 \%$ of urban population lived in areas with high potential for ATES at the start of the 21 st century, but this figure will decrease to about $5 \%$ during the 21 st century as a consequence

\footnotetext{
* Corresponding author at: Delft University of Technology, Department of Water Management, PO Box 5048, 2600 GA, Delft, The Netherlands. E-mail address: j.m.bloemendal@tudelft.nl (M. Bloemendal).
} 
of expected climate change. Around 50\% of urban population currently lives in areas of medium ATES suitability, a percentage that will remain constant. Demand for ATES is likely to exceed available subsurface space in a significant part of the urban areas.

(C) 2015 Elsevier B.V. All rights reserved.

\section{Introduction}

\subsection{Principle and development of ATES Technology}

Buildings in moderate climates generally have a heat surplus in summer and a heat shortage in winter. Where aquifers of sufficient capacity exist, this temporal discrepancy can be overcome by seasonal storage in and extraction of thermal energy from the subsurface. An Aquifer Thermal Energy Storage (ATES) system generally consists of one or more pairs of tube wells, so called doublets that extract and simultaneously infiltrate groundwater to store and extract thermal energy in aquifers by changing the groundwater temperature by means of a heat exchanger (Fig. 1).

ATES is applied worldwide (Blum et al., 2010; Eugster and Sanner, 2007; Fry, 2009; Verbong et al., 2001; Yang et al., 2010); overviews of application of ATES show growth, and in some countries even exponential growth (Bertani, 2005; Bonte, 2013; Lund et al., 2004, 2011; Lund and Freeston, 2001; Sommer, 2015). Adoption is mainly driven by energy saving targets, set by international and national energy saving agreements (EU-Parliament, 2010; SER, 2013). In most countries, however, adoption of ATES technology is limited because of competition by fossil fuels combined with economic recession, preventing people to invest in ATES (Hoekstra et al., in press). Lack of knowledge regarding potential and (future) applicability of ATES is one of the main other important barriers for its application in several European countries (Hoekstra et al., in press; Geo.Power, 2012; Ground-reach, 2007).

Legislation for shallow geothermal energy storage systems, including, ATES and Borehole Thermal Energy Storage ${ }^{1}$, varies between countries (Aebischer et al., 2007; Bloemendal et al., 2014; Hoekstra et al., in press; Geo.Power, 2012; Ground-reach, 2007; Haehnlein et al., 2010). Specific legislation was developed in countries where ATES is applied or it was altered to properly govern and/or stimulate the technology. Dedicated legislation is either lacking or poorly substantiated in countries with little application of ATES (Haehnlein et al., 2010), even though it's technical potential may be or will become high. This might result in suboptimal and unsustainable use of the subsurface for ATES or even prohibit application of the technology (Bloemendal et al., 2014). Therefore, it is important for governments to prepare for the potential growth of ATES systems and adapt legislation and groundwatermanagement practice if needed. A key aspect to such preparation is identification of areas that indicate the suitability for ATES and show potential hot-spots for ATES systems.

Based on developments discussed above and socio-economic developments such as economic growth, sustainable energy targets and high energy prices, it is expected that in the future more buildings can and will rely on ATES in the future for their space heating and cooling, but only when local conditions are suitable and are known to be so.

\subsection{Problem statement}

Lack of insight in potential, poorly substantiated legislation and/or socio-economic factors are among the main reasons why ATES is not adopted in many countries (Hoekstra et al., in press). These barriers have

\footnotetext{
1 Borehole thermal energy systems (BTES) also exists. These systems do not use the groundwater as transport medium, the thermal energy transfer only goes through conduction with a closed pipe in the subsurface. For these type of systems the subsurface conditions are less crucial.
}

to be razed to allow ATES to contribute significantly to $\mathrm{CO}_{2}$-emission reduction. A worldwide overview showing where ATES technology is likely to be, or becomes successfully applicable, may foster the technology. Such an overview would help governments to substantiate their regulation and to stimulate ATES application to meet their energy saving goals.

\subsection{Method}

Climatic conditions and the availability of a suitable aquifer are the two most important conditions for the applicability of ATES. Georeferenced climate and geo-hydrological conditions are combined to identify areas with suitability for ATES. ATES suitability maps are combined with projections of population in urban areas ${ }^{2}$ to identify ATES hot-spots. Different sources of geographically referenced properties and conditions are combined and evaluated to identify the suitability for any building in a specific area. This method is similar with multi criteria decision analysis (MCDA) as it is often applied in spatial planning (Malczewski, 1999, 2006), however, in our case the evaluation purpose is not decision making. Methods used for MCDA available in literature are, therefore, only partly applicable. Nevertheless, we apply 5 of the 8 steps $^{3}$ that were introduced by Ferretti (Ferretti, 2011).

I) Data acquisition. We selected four sources of data that we combined into a world map of ATES suitability: 1) occurrence and properties of aquifers and groundwater (BGR and UNESCO, 2008; Richts et al., 2011), 2) climate classification (Kottek et al., 2006) and 3) urbanization data (Ahlenius, 2014; United Nations, 2008).

II) Problem structuring. The available datasets were not composed with the purpose to identify ATES suitability, their characteristics had to be converted to ATES suitability. The attributes of the data sets were evaluated and their mutual suitability was determined based on the requirements for ATES systems. In Section 2 this done for the geo-hydrological conditions and in Section 3 for the climatic conditions.

III) Comparison. This step consists in the identification of the ATES suitability for each geo-referenced unit relative to others. Each database entry is given an ATES suitability score relative to the other entries of that same property, based on the mutual suitability which was defined in step II.

IV) Standardization \& Validation. The obtained relative suitability scores are standardized to a uniform scale to enable combining and comparing different intermediate maps. In the standardization step we introduced an extra step, namely the validation of the suitability score. We do so by applying scale factors, that can be altered to obtain the required result (detailed explanation in Section 2). Because a frame of reference or assessment

\footnotetext{
2 ATES works at low temperature thermal energy, to prevent losses this energy can only be transported over small distances. Therefor ATES is only applied where the building is close by resulting in the fact that demand for heating and cooling with ATES is typically present in urban areas.

${ }^{3}$ Due to the differences in nature and spatial reference of the available data, the super matrices formation was not applicable in this study. The results aggregation is in this study more or less the same step as the standardization and is therefore incorporated in that step. Ferretti questions the applicability of a sensitivity analysis herself. Applying a sensitivity analysis is not common in the field of MCDA because it is complex in a spatial multi criteria evaluation (Ferretti, 2011). In this research the data used for the analysis consist of three different datasets with different composition and/or properties, making it even more laborious.
} 

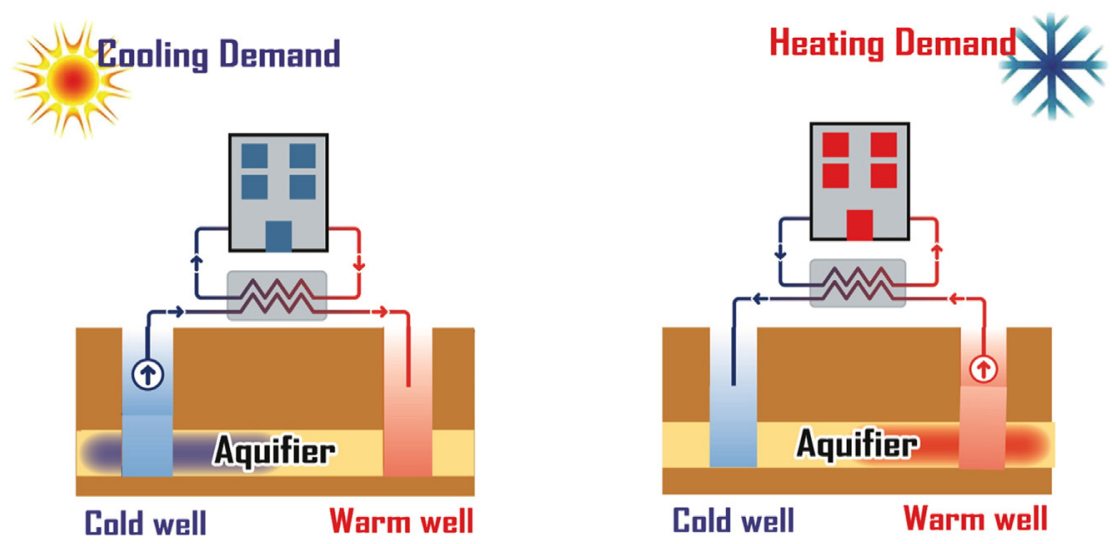

Fig. 1. Basic principle of ATES.

framework was not available, the validation of the obtained results was an important aspect of this research.

We define ATES suitability from low to high on a 1 to 10 scale. This allows for enough level of detail and provides as clear differentiation between high, medium and low-suitable areas as well.

V) Processing. The determined suitability scores are processed with a Geographical-Information-System (GIS) into a map displaying the ATES-suitability's.

The schematic overview In Fig. 2 shows how steps I and V relate in this research. Steps II, III and IV are located in the gray blocks; a detailed scheme for those steps is given in the corresponding sections of this paper. Different data sets were used, forcing to carry out some of the steps explained above multiple times on different datasets.

Section 2 and 3 discuss the method and results to translate geohydrological and climatic data respectively into ATES suitability. The results are then combined and discussed in relation to urbanization data to identify the hot-spots in Section 4. A discussion and conclusion follow in Section 5.

\section{Geo-hydrological ATES suitability}

\subsection{Translating subsurface properties to ATES suitability}

Detailed information is required to determine geo-hydrological suitability for ATES application. General available geo-hydrological data lacks the required level of detail. Nevertheless, aquifer suitability for ATES can be estimated worldwide by assessing available worldwide aquifer characteristics and groundwater data as explained in Section1.3.
Fig. 3 shows the steps required to obtain the geo-hydrological ATES suitability scores. Steps III and IV that are specific for determination of the geo-hydrological suitability are described below.

III) Comparison; Assessment of mutual suitability. It is not possible to derive ATES suitability directly from these data, because the data regarding the subsurface originate from different databases that have many different attributes (BGR and UNESCO, 2008; Richts et al., 2011). We may, however, base the relative ATES suitability of locations on geo-hydrological properties in the available data sets.

IV) Standardizing and Scaling. Applying a scale factor for each characteristic allows combining the different characteristics into an ATES suitability value. The analysis results in a calculation scheme similar to a multi-criteria analysis. A first estimate of the scaling factors was determined by the author's expert judgment.

IV) Validating. The so-obtained worldwide ATES suitability scores were then validated using already available detailed ATES suitability maps (Geo.Power, 2012), known adoption rates (Hoekstra et al., in press; Geo.Power, 2012; Ground-reach, 2007) and detailed subsurface characterization maps for Europe (Karrenberg, 1976). The scaling factors were manually altered to make the obtained suitability scores match the expected suitability score based on the local detailed information and characterization.

\subsection{Translation of geo-hydrological conditions to ATES suitability (II: problem structuring)}

Identifying the places with suitable aquifers for the application of ATES systems requires definition of aquifer properties that facilitate application of such systems. ATES can be applied in aquifers with sufficient capacity, so tube wells can be installed and operated (NVOE, 2006).

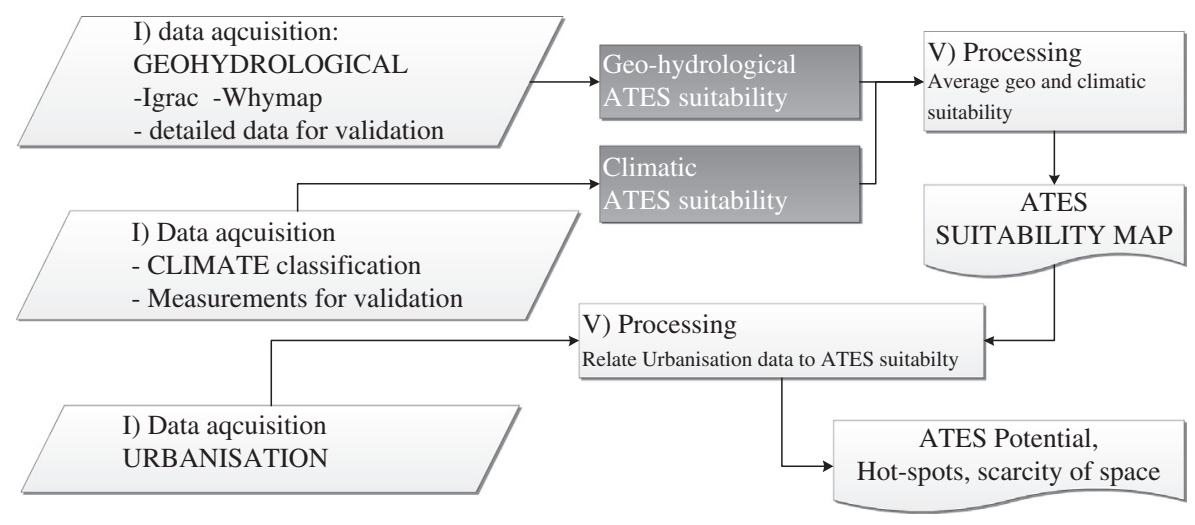

Fig. 2. Schematic overview of approach to determine ATES suitability. 


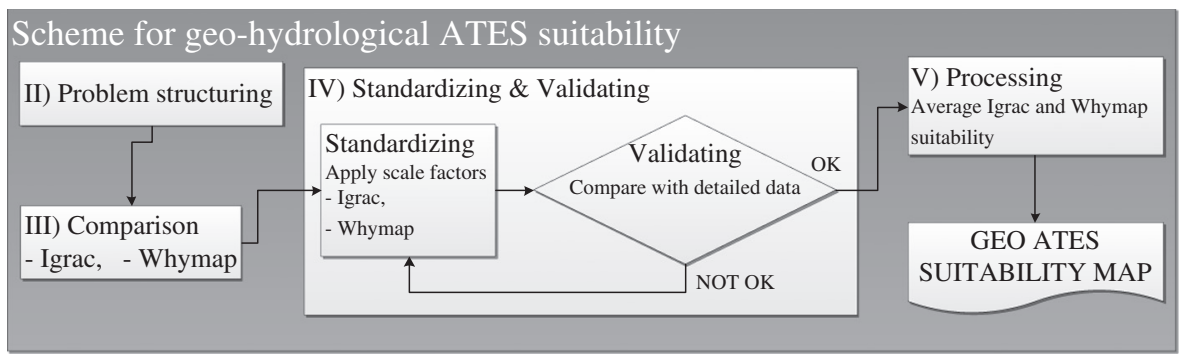

Fig. 3. Approach to determine Geo-hydrological ATES suitability.

The specific geo-hydrologic properties on which efficient operation and design of ATES systems depends is explained in the following bullets.

- Water quality. Groundwater quality conditions determine the life expectancy of ATES wells and their required maintenance. Groundwater from different depths of the aquifer is mixed in extraction wells and then re-injected in injections well, and vice versa in the next season. When the chemical composition of the groundwater varies over the depth of the aquifer, mixing of these different water qualities may result in chemical reactions that affect well performance by forming chemical precipitations, leading to clogging of filter screens. As an example mixing of reduced iron-rich water with oxygenated water, leads to clogging by iron-ferric-hydroxides (iron flocs) in the receiving well screen (Beek, 2010). ATES systems in polluted groundwater also tend to be vulnerable to clogging as well as to corrosion, especially when operating in brackish groundwater (Zuurbier et al., 2013). Shallow aquifers below urban areas often carry such water-quality differences and contaminations; these types of aquifers are less suitable for ATES. Aquifers less than $50 \mathrm{~m}$ deep are considered shallow in our framework.

- Fresh vs. saline water. ATES can be applied in both fresh and saline aquifers, but saline water requires salinity-resistant equipment to prevent corrosion. Therefore, ATES, is cheaper and less sensitive to maintenance in fresh aquifers. Suitable aquifers with fresh water below urban areas will often be intensively exploited, thus offering little potential for use of ATES that may interfere with extractions of groundwater.

With many urban areas developing near coasts, the local groundwater may be brackish or saline, with little or no use to domestic users or agriculture. This offers an opportunity to apply ATES. In coastal aquifers, the transition from fresh to saline groundwater resides generally in relatively shallow aquifers. It is often not allowed to influence this interface to prevent salinization, see for instance (Delfland, 2010). Salinity generally increases with depth. Extracting from and infiltrating water in a salinity-stratified aquifer results in buoyancy-flow that is driven by density differences; this effect decreases the thermal efficiency of the ATES wells (Caljé, 2010). Freshwater aquifers are preferable but groundwater from such aquifers is also used, for drinking water production or irrigation so that ATES often has to compete with limiting its applicability.

- Ambient groundwater flow. Even though groundwater displacement is generally not fast in most cases, less than say $25 \mathrm{~m} / \mathrm{year}$, the associated advection of the thermal energy stored in it may cause loss of efficiency of ATES systems, which generally have a thermal radius within the aquifer in the range from 25 to $100 \mathrm{~m}$ (Bloemendal, 2010). The efficiency of larger ATES systems is less affected by ambient groundwater flow than that of small systems, but still losses due to groundwater advection may be substantial. In any case, aquifers with higher groundwater flow rates are less suited to store thermal energy.

- Composition of the aquifer. Any layering, heterogeneity, fissures, fractures and faults negatively affect thermal efficiency of ATES systems. High hydraulic conductivities often imply larger advection rates and associated advection losses, while heterogeneity implies zones with higher and lower velocities causing lateral loss of heat by heat exchange with confining layers and less pervious structures having different temperatures due to slow exchange, thus adding to heat dispersion (Sommer et al., 2015). Vertical anisotropy, however, is a benefit for ATES systems since it limits vertical flow losses. Fissures, fractures and faults are likely to cause preferential flow paths with extreme lateral loss of thermal energy through exchange with the aquifer blocks in between the fractures, in which the flow rate may be orders of magnitude less than in the fractures. In aquifers with faults or fractures, it is difficult to control where the stored water flows and with that the thermal energy. As a consequence of geologic processes, aquifers and their enclosing layers may have been tilted. In tilted aquifers with nearby outcrops/recharge zones, groundwater flow is often high and waterquality conditions are likely to vary. These aspects make complex hydrological structures less suitable for ATES application.

- Depth of Aquifer. Aquifer depth below ground surface is of little importance from the perspective of energy efficiency, but it affects well drilling and installation cost. While larger depths may imply salinity issues, shallower depths tend to encounter water-quality issues as was outlined above. The optimal depth is often a trade-off between installation costs (the shallower the better), expected problems with water quality (the deeper the better) and efficiency (the more uniform the composition and groundwater quality the better).

\subsection{Subsurface characteristics translated to ATES suitability (III: comparison, IV: standardizing \& validating)}

UNESCO and BGR (Richts et al., 2011) constructed the WHYMAP transboundary aquifer maps with associated data that include two types of characteristics useful to derive ATES suitability from; 1 ) the composition of the aquifers and 2) the amount of recharge. IGRAC on the other hand, made an overview on a country by country basis for many different subsurface and groundwater characteristics (BGR and UNESCO, 2008) utilizing over 450 different sources to compose its maps and database. The data comprises four main types of characteristics: 1) extent per aquifer type for each country as a percentage of the country's surface area, 2) occurrence of highly productive aquifers per country as a percentage of the country's surface area, 3) mean annual recharge, and 4) groundwater abstraction as a percentage of the country's water consumption. In the following, the relative suitability for ATES is defined for these characteristics.

Occurrence and type of aquifer. By definition, aquifers contain groundwater, making aquifer occurrence an important characteristic for ATES suitability. The scaling factor that is used for this characteristic is called $F_{a q}$. Within this characteristic, distinction is made between:

Major groundwater basins such as sand aquifers, gravel aquifers and inter-granular aquifers. These generally are vast with a constant-intime water quality and a high hydraulic conductivity. Areas with major groundwater basins are the most suitable, even if some of them might have too low a hydraulic conductivity for ATES application.

O Local and shallow aquifers are also generally suitable for ATES 
Table 1

Relative ATES suitability of WHYMAP characteristics.

\begin{tabular}{|c|c|c|c|c|}
\hline \multicolumn{2}{|c|}{$\begin{array}{l}\text { Relative suitability of aquifer characteristics } \\
\left(s_{-} a q, j\right)\end{array}$} & \multicolumn{2}{|c|}{$\begin{array}{l}\text { Relative suitability of groundwater recharge } \\
\left(s \_g w, j\right)\end{array}$} & \multirow{2}{*}{$\begin{array}{l}\text { Calculated ATES suitability } \\
\left(S_{\lrcorner} j\right) \\
7.2\end{array}$} \\
\hline Major groundwater basin & 3 & $<2 \mathrm{~mm} / \mathrm{y}$ & 0 & \\
\hline Major groundwater basin & 3 & $2-<20 \mathrm{~mm} / \mathrm{y}$ & 1 & 7.9 \\
\hline Major groundwater basin & 3 & $20-<100 \mathrm{~mm} / \mathrm{y}$ & 2 & 8.6 \\
\hline Major groundwater basin & 3 & $100-<300 \mathrm{~mm} / \mathrm{y}$ & 3 & 9.3 \\
\hline Major groundwater basin & 3 & $>=300 \mathrm{~mm} / \mathrm{y}$ & 4 & 10 \\
\hline Complex hydrogeological structure & 1 & $<20 \mathrm{~mm} / \mathrm{y}$ & 1 & 1.0 \\
\hline Complex hydrogeological structure & 1 & $20-<100 \mathrm{~mm} / \mathrm{y}$ & 2 & 1.7 \\
\hline Complex hydrogeological structure & 1 & $100-<300 \mathrm{~mm} / \mathrm{y}$ & 3 & 2.4 \\
\hline Complex hydrogeological structure & 1 & $>=300 \mathrm{~mm} / \mathrm{y}$ & 4 & 3.1 \\
\hline Local and shallow aquifers & 2 & $<100 \mathrm{~mm} / \mathrm{y}$ & 2 & 5.2 \\
\hline Local and shallow aquifers & 2 & $>=100 \mathrm{~mm} / \mathrm{y}$ & 3 & 5.8 \\
\hline Scaling factor (F_aq) & 5 & Scaling factor ( $\left.F_{\lrcorner} g w\right)$ & 1 & \\
\hline
\end{tabular}

application because the local scale and impact of ATES systems does not require an extensive aquifer. Shallow aquifers may, however, pose problems due to water-quality issues that cause clogging of the wells as shallow urban aquifers are often contaminated. Because of these considerations the shallow and local aquifers were ranked to be of medium suitability.

O ATES suitability in so-called complex hydrological structures such as tilted aquifers, karstified aquifers, fissured and fractured rock aquifers, always strongly depends on local conditions. Since ATES is a local-scale technology, there may be zones within complex structures that are suitable for ATES application. Mostly, however, ATES systems will not be easily applicable or even possible in such complex formations, because of which such formations are ranked to be of lowest suitability.

Groundwater. Information about groundwater may also indicate about ATES suitability, especially when no other information is available. A second scaling factor is applied to deal with characteristics, denoted $F_{g w}$. Within the groundwater properties distinction is made between:

$\bigcirc$ Groundwater recharge, the yearly percolation into local aquifers. In some locations recharge is the only information in the databases that can be linked to groundwater availability. Despite the fact that recharge is a poor indicator for groundwater availability, it is used in characterizing ATES suitability; the more there is the higher is the probability that ATES can be applied.

O Production from aquifers. This characteristic is more important for ATES applicability than is groundwater recharge, because it provides actual information on how much water can be produced from the considered aquifer. So the more water produced from aquifers, the more suitable it is considered for ATES. There are two remarks, however: 1) areas with saline groundwater will thus end-up low in the ranking because these are not contained in the groundwater data while still suitable for ATES systems, and 2) in fresh water aquifers, ATES has to compete with irrigation, industrial and drinking water production, which constraints ATES application.

With this analysis, the different characteristics available in the WHYMAP and IGRAC databases allows ranking of ATES suitability on a worldwide scale according to step III and IV of the method described in Sections 1.3 and 2.1. For these datasets, we established ATES suitability using a calculation scheme, explained next. The calculation method applies the scaling factors $F_{a q}$ and $F_{g w}$. We apply the same scaling factors in the analysis of both datasets because the relative importance of different data types cannot depend on the source of the data with the same trustworthiness.

Both datasets were validated individually with respect to the actual ATES suitability based on detailed aquifer and groundwater information from 5 selected countries in Europe. The thus obtained ATES suitability scores from these countries were used to optimize the scaling factors $F_{a q}$ and $F_{g w}$, such that the obtained suitability scores match the expected suitability based on detailed local information as closely as possible.

Despite the limited number of characteristics we chose to use these data because the WHYMAP database is a complete set that covers the whole world and has a detailed spatial reference that matches geohydrological units. The calculation of the ATES suitability scores for the WHYMAP data $\left(S_{j}\right)$ is described in Eq. (1), the subscript " $j$ " refers to the parameters location, $X_{j}$ represents the standardization factor. The other symbols are explained in Table 1, which contains the WHYMAP data characteristics. Columns 1 and 2 show the aquifer characteristics with their relative importance based on the analysis described in Section 2.1 and above, these columns result from the comparison operation. Columns 3 and 4 show the relative importance of the groundwater recharge based on the analysis described in Section 2.1 and above. Column 5 contains the ATES suitability normalized between 1 and 10 . It was obtained by first multiplying the scores in column 2 and 4 with the scale factor in the corresponding column of the bottom row, adding them and normalizing (with $X_{j}$ ) afterwards.

$S_{j}^{\text {whymap }}=\left(\chi_{a q}^{\text {whymap }} \cdot F_{a q} \cdot s_{a q, j}^{\text {whymap }}+\chi_{g w}^{\text {whymap }} F_{g w} \cdot s_{g w, j}^{\text {whymap }}\right)$

Table 2 contains the IGRAC data for 5 selected countries in Europe on which the validation was based. The IGRAC dataset characteristics and their spatial reference differ very much from the WHYMAP data. Firstly, the IGRAC database contains many more and more detailed characteristics, and secondly, the spatial reference is based on countries instead of geo-hydrological units. Unfortunately, many characteristics are only available for a few countries and, therefore, had to be excluded from this analysis. The remaining characteristics used for the analysis, are presented in Table 2, but even these were not complete for all countries. For the countries with missing data with respect to the used characteristics, the ATES suitability was based on only the remaining available characteristics. Eqs. (2), (3) and (4) show how the IGRAC ATES suitability score is calculated, again $X$ represent the standardization factor, the other symbols are explained in the following and indicated in Table 2.

Table 2, columns 2, 3, 4 and 5, 6, 7 contain the extent of the countries' surface area with a certain aquifer property as a percentage of the counties surface area. The number should add up to $100 \%$, but some don't, as was explained earlier. The numbers in these columns below row 3 are the areal percentage within each country $(P)$, which are weighted by multiplying them with the relative aquifer suitability shown in row $2\left(s_{\#}\right)$ and the corresponding scale factor given in the bottom row, similar to the calculation scheme in Table 1. Columns 8 and 9 refer to groundwater properties, with column 8 recharge rate, which was truncated at a maximum of $300 \mathrm{~mm} / \mathrm{y}$ to prevent outliers, and column 9 holds the groundwater abstraction relative to total water consumption. Both the recharge rate and the abstraction 
Table 2

Relative ATES suitability of used IGRAC characteristics.

\begin{tabular}{|c|c|c|c|c|c|c|c|c|c|}
\hline \multirow[b]{2}{*}{$\begin{array}{l}\text { Relative suitability } \\
\left(s_{\_} \#\right)\end{array}$} & \multicolumn{6}{|c|}{ Relative suitability of aquifer characteristics } & \multicolumn{2}{|c|}{$\begin{array}{l}\text { Relative suitability of groundwater } \\
\text { characteristics }\end{array}$} & \multirow[b]{3}{*}{$\begin{array}{l}\text { Calculated } \\
\text { ATES } \\
\text { suitability } \\
\left(S_{-} j\right)\end{array}$} \\
\hline & 2 & 1 & 0 & 2 & 1 & 0 & 1 & 3 & \\
\hline Country & $\begin{array}{l}\text { Extent of } \\
\text { intergranular } \\
\text { aquifers } \\
\left(P_{-} i\right)\end{array}$ & $\begin{array}{l}\text { Extent of } \\
\text { fissured } \\
\text { aquifers } \\
(P f)\end{array}$ & $\begin{array}{l}\text { Extent of } \\
\text { areas without } \\
\text { aquifers } \\
\left(P_{-} 0\right)\end{array}$ & $\begin{array}{l}\text { Extent of } \\
\text { productive } \\
\text { intergranulas } \\
\text { aquifers }\left(P_{-} p i\right) \\
\end{array}$ & $\begin{array}{l}\text { Extent of } \\
\text { productive } \\
\text { fissured aquifers } \\
\left(P \_p f\right)\end{array}$ & $\begin{array}{l}\text { Extent of zones } \\
\text { without } \\
\text { groundwater } \\
\left(P \_p 0\right)\end{array}$ & $\begin{array}{l}\text { Mean annual } \\
\text { groundwater } \\
\text { recharge }(\mathrm{mm} / \mathrm{y}) \\
\left(R_{\lrcorner} j\right)\end{array}$ & $\begin{array}{l}\text { GW extraction as a \% } \\
\text { of total water } \\
\text { consumption } \\
\left(P_{-} \text {ext }\right)\end{array}$ & \\
\hline Belgium & 29 & 33 & 38 & 18 & 16 & 35 & 29 & 4 & 3.5 \\
\hline Germany & 41 & 33 & 24 & 26 & 18 & 16 & 128 & 4 & 4.0 \\
\hline Netherlands & 99 & 1 & 0 & 61 & 1 & 0 & 108 & 1 & 10 \\
\hline Spain & 20 & 15 & 65 & 8 & 11 & 17 & 59 & 5 & 2.2 \\
\hline United Kingdom & 10 & 28 & 62 & 4 & 10 & 48 & 40 & 1 & 1.3 \\
\hline Scaling Factor & $F_{-} a q=5$ & & & & & & $F \_g w=1$ & & \\
\hline
\end{tabular}

percentages were normalized between 1 and 10 before multiplying them with the suitability factors in row 2 and the scale factor in the bottom row and summing the column results. Finally, the three sets of columns were combined by multiplying the normalized scores with the corresponding scaling factors in the bottom row, and then taking the sum, of which the results are shown in the right-most column of Table 2.

$S_{j}^{i g r a c}=\left(F_{a q} \cdot S_{a q, j}^{i g r a c}+F_{g w} \cdot S_{g w, j}^{i g r a c}\right)$

$s_{a q, j}^{i g r a c}=\chi_{a q}^{i g r a c}\left(P_{j}^{i} \cdot s_{j}^{i}+P_{j}^{f} \cdot s_{j}^{f}+P_{j}^{p i} \cdot s_{j}^{p i}+P_{j}^{p f} \cdot s_{j}^{p f}\right)$

$s_{g w, j}^{\text {igrac }}=\chi^{\text {rech }} \cdot s_{j}^{\text {rech }} \cdot R_{j}+\chi^{e x t} \cdot s_{j}^{e x t} \cdot P_{j}^{e x t}$

\section{Validation procedure}

The ATES suitability calculation is based on 1) database properties, 2) the relative suitability of characteristics and 3) the scaling factor. The database properties cannot be altered and the relative suitability simply follows from the problem structuring step (II) in Section 2.2 and is thus also fixed. The only manipulated parameters in the validation procedure are the two scaling factors. Allowing more than 2 scaling factors would give more opportunity for optimization during the validation and may result in a more representative and more detailed suitability map. This approach would make the validation process more complex and more difficult to explain and understand, while the data did not warrant a more sophisticated analysis and calibration. In addition, no frame of reference is available to allow quantification of the validation. Therefore, it was chosen to rely mainly on the datasets and the relative suitability's defined in our analysis in Section 2.1 and above, and limit our optimization to only 2 scaling factors to allow for corrections on the found suitability's.

Existing general ATES suitability maps and adoption rates (Hoekstra et al., in press; Geo.Power, 2012; Ground-reach, 2007) were used to validate the IGRAC ATES suitability scores. As a consequence of the diversity in the attributes and geographical reference in the validation data, it was not possible to identify a single expected suitability score to base the validation on. Therefore, the validation was carried out at a 3-scale basis as follows: for each of the selected countries/areas it was defined whether the ATES suitability is good, medium or poor. Subsequently, during validation, the obtained scores where fit within the corresponding bandwidth of suitability score: poor $=1-3$, medium $=4-6$, good $=7-10$. The detailed European aquifer characterization maps (Karrenberg, 1976) were used to validate our scoring based on the WHYMAP data. Without going into detail about the characteristics of the reference map, the validation data and corresponding results in the form of a suitability map are given in Fig. 4 as an example of how the validation was carried out. For the validation of the IGRAC data, local information about ATES adoption and application research (Hoekstra et al., in press; GEO.POWER, 2012; GROUND-REACH, 2007) were used to define if the ATES suitability of the selected countries is good, medium or
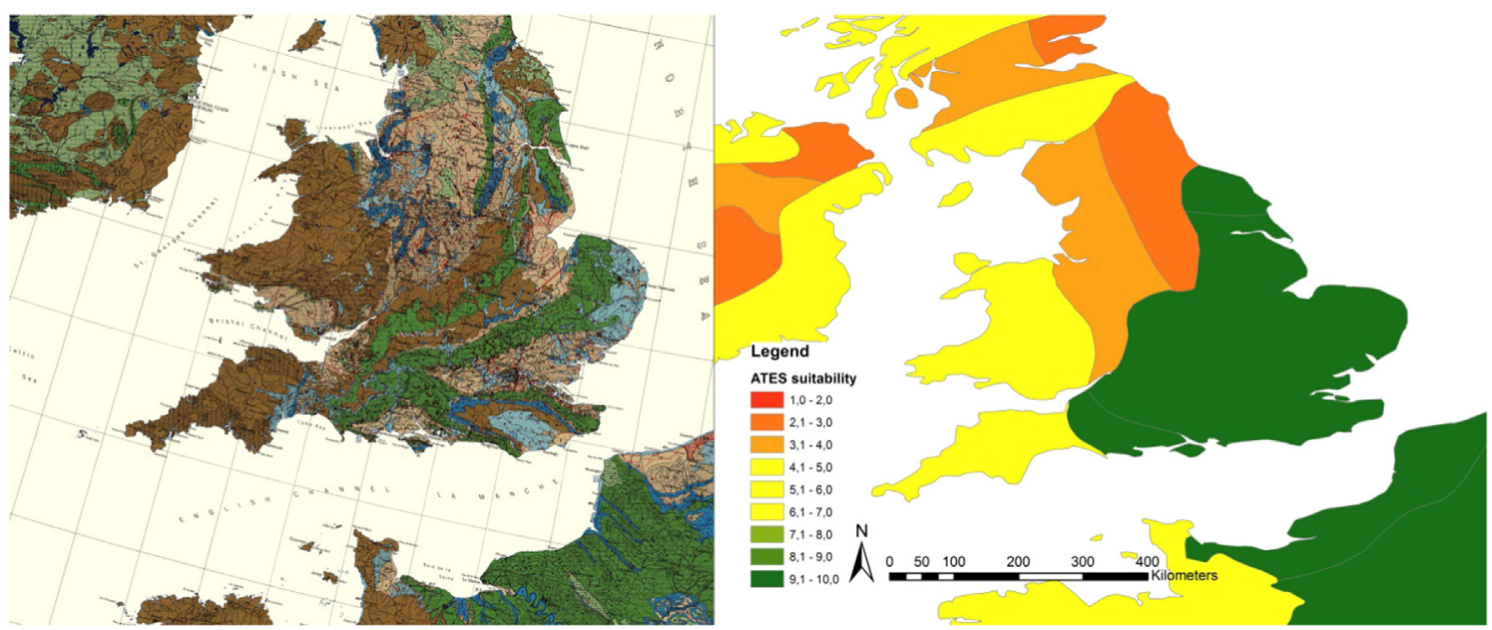

Fig. 4. Detailed characterization map (Karrenberg, 1976) and the WHYMAP suitability score map of South-West Britain. 


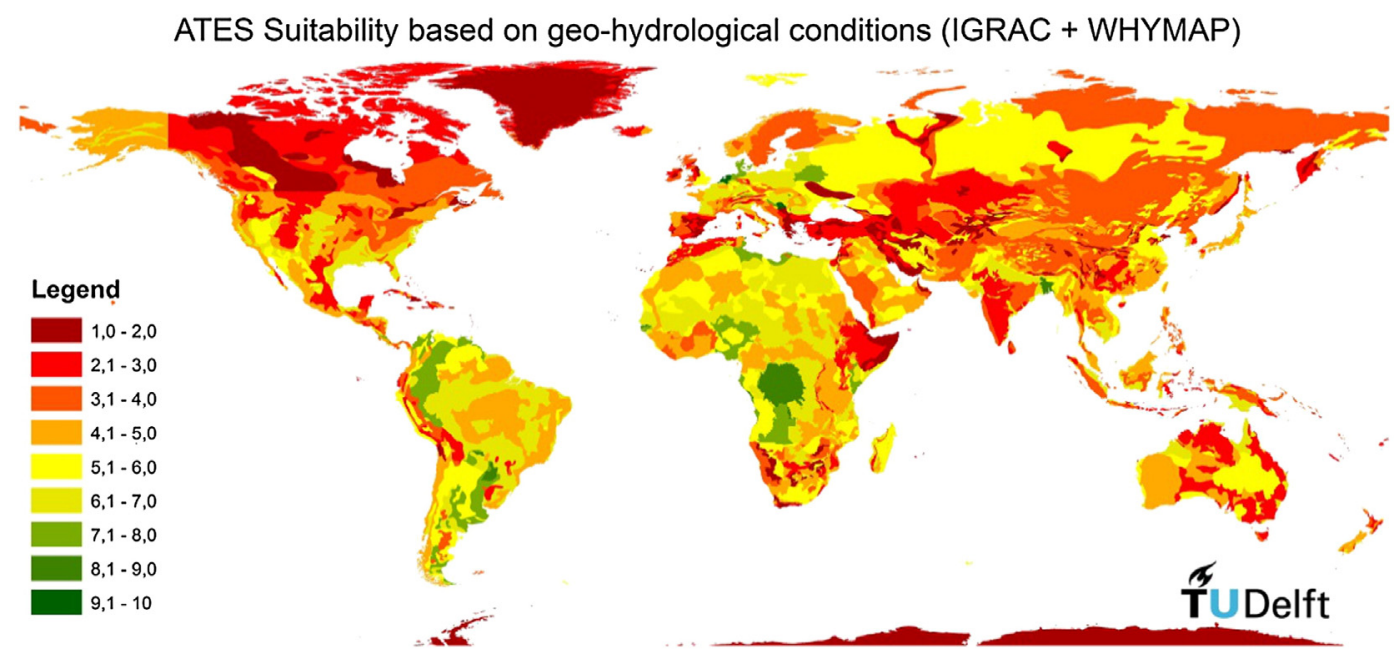

Fig. 5. ATES suitability based on WHYMAP \& IGRAC data.

poor. The validation step taught us that the conditions regarding aquifer characteristics rather than groundwater characteristics dominate the determination of ATES suitability.

\subsection{Result and discussion of geo-hydrological suitability for ATES (V: processing)}

After the validation, we combined the obtained ATES suitability scores from both data sets by averaging them in a GIS-environment $\left(S^{G E O}=\left(S^{\text {whymap }}+S^{\text {igrac }}\right) / 2\right.$. The suitability map resulting from the exercises explained in this section is given in Fig. 5.

The surface area with high suitability is limited to about 5\%, in most places the subsurface conditions are medium suitable ( $65 \%)$ for application of ATES. This is due to the difference between the results of the two data sets. The IGRAC data tend to give lower results than the WHYMAP data, the average score differs 3 points. In $40 \%$ of the areas, the difference is smaller than 3 suitability points. However, in $75 \%$ of the cases the results from the data sets agree on if a suitability score is higher or lower than their average score or the suitability score differs less than 3 points. The differences in the remaining $25 \%$ of the areas can be explained by considering two aspects:

- IRGAC lumped aquifer characteristics to country-averaged values, while WHYMAP lumped its data by geological formation. For large countries, this biases the result, as can be seen at the border between the USA and Canada. Also, the results show that large countries like USA, Russia, Brazil, Argentina and Australia, tend to have many areas of medium suitability. While IGRAC data were useful for smaller countries, these country lumped data are not accurate enough to deduce ATES suitability for bigger ones. This leads to the recommendation towards IRGAC to rather collect data per state, province, county or district in bigger countries.
- The IGRAC database requires data collection and validation for each country, which is lacking in many less developed countries (Jerven, 2013), resulting in incomplete data sets. It is very likely that many African countries are in the medium range of suitability due to this effect.

Groundwater quality is an important aspect for ATES systems. Since only limited groundwater quality information is present in the available datasets, groundwater quality could only be considered implicitly by considering shallow aquifers to be less suitable. This implies that deviations from the presented maps are possible due to groundwater-quality issues when using the ATES suitability map in practice.

The ATES suitability map was constructed from different data sources. Where the different sources agree on their ATES suitability, it is reasonable to assume that the map gives a correct representation of ATES potential. Areas scoring in the middle range between 4 and 7, is in many cases the result of averaging higher and lower suitability values where the scored WHYMAP and IGRAC data sources did not match. Further development of this map should, therefore, focus on these areas. Given that the validation is only based on detailed maps from Europe and data of the WHYMAP and IGRAC are not congruent, a likely follow-up is to explore how an extra scaling factor that distinguishes between the relative contribution of each dataset, would improve the results with in combination with an extra validation with detailed information about ATES applicability from other continents.

\section{Where do climatic conditions favor ATES suitability?}

\subsection{Method for translating climatic conditions to ATES suitability}

To identify where the climate is suitable for ATES we define relevant climatic conditions. Climate control in buildings and their resulting

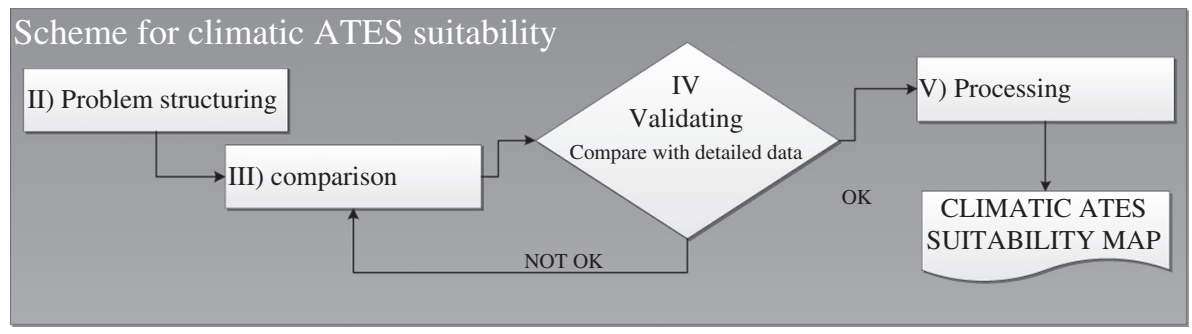

Fig. 6. Schematic overview of approach to determine ATES suitability. 
Table 3

Temperature thresholds for energy balance and ATES suitability.

\begin{tabular}{|c|c|c|c|c|}
\hline & Average outside air temperature $[\mathrm{C}]$ & Energy balance & Suitability for ATES & Score (S_Clim) \\
\hline A & $>25$ & Mainly cooling demand, no heating demand & Hardly & 1 \\
\hline B & $20<$ Tavg $<25$ & Prevailing cooling demand, small heating demand & Specific buildings & 4 \\
\hline $\mathrm{C}$ & $15<$ Tavg $<20$ & Heating and cooling demand (more or less) balance & Most buildings & 10 \\
\hline $\mathrm{D}$ & $10<$ Tavg $<15$ & Prevailing heating demand, small cooling demand & Specific buildings & 6 \\
\hline $\mathrm{E}$ & $<10$ & Mainly heating demand, no cooling demand & Hardly & 2 \\
\hline
\end{tabular}

demand for thermal energy storage depends, among others, on climate. To translate general climate data to ATES suitability was done in 5 steps, of which II to V are schematically shown in Fig. 6. Steps III and IV are described as follows:

III. Assign an ATES suitability score to each climate class. The 31 Koeppen climate classes (Kottek et al., 2006; Rubel and Kottek, 2010; Vetmed uni Vienna, 2014) were divided in ATES suitability classes based on individual climate-class characteristics such as average temperature levels and yearly variation in temperature (Chen, 2014; Pidwirny, 2011) taking into account properties and use of buildings.

IV. Validation. Actual climate data of locations were used to validate our climate-based suitability classification obtained in step 1.

3.2. Climate classifications translated to demand for space heating and cooling (II: problem structuring)

For optimal efficiency and to sustain an ATES system about as much thermal energy has to be stored and extracted on average. Balancing seasonal heat extraction and storage prevents ongoing growth of either of the warm or cold zone in the subsurface, which would ultimately negatively affect the extraction temperature of the other well of the system, or neighboring wells (Bloemendal et al., 2014; NVOE, 2006; Sommer et al., 2013). Therefore, suitability for ATES depends on the energy demand of the connected building, that it depends on climate conditions. The balance between cooling demand in summer and for space heating demand in winter however, also depends on building properties and building use, like orientation, insulation and internal heat load as caused by computers, occupancy and lighting. Therefore, climate, properties of buildings and use of buildings must be considered jointly to determine whether buildings in a region may benefit from application of ATES. It is practically impossible to incorporate building properties in an ATES suitability map as that would result in a wide range of different conditions and thresholds for suitability. To allow defining suitability of ATES for a given region solely on climate data, the following simplifications and assumptions were made:

- It is relatively expensive and inefficient to install an ATES system in an (existing) poorly insulated building, Therefore ATES is mainly

Table 4

Climate classification linked to ATES suitability.

\begin{tabular}{|c|c|c|c|}
\hline Code & Description & Validation (S_Clim) & Suitability (S_Clim) \\
\hline \multicolumn{4}{|c|}{ GROUP A: Tropical/megathermal climates } \\
\hline Af & Equatorial rainforest, fully humid; precipitation $\geq 60 \mathrm{~mm} / \mathrm{month}$ & 1 & 1 \\
\hline Am & Equatorial monsoon climate & 1 & 1 \\
\hline As & Equatorial savannah with dry summer Pmin $<60 \mathrm{~mm}$ in summer & - & 1 \\
\hline Aw & Equatorial savannah with dry winter Pmin $<60 \mathrm{~mm}$ in winter & 2 & 1 \\
\hline \multicolumn{4}{|c|}{ GROUP B: Dry (arid and semiarid) climates } \\
\hline BWk & Cold Desert, average temperature $<18^{\circ} \mathrm{C}$ & 4.3 & 10 \\
\hline BWh & Warm Desert, average temperature $>18^{\circ} \mathrm{C}$ & 2.3 & 4 \\
\hline BSk & Cold Savanna, average temperature $<18^{\circ} \mathrm{C}$ & 5.3 & 6 \\
\hline BSh & Warm Savanna, average temperature $>18^{\circ} \mathrm{C}$ & 5 & 4 \\
\hline \multicolumn{4}{|c|}{ GROUP C: Temperate/mesothermal climates } \\
\hline $\mathrm{Cfa}$ & Warm sea-climate, average temperature hottest month $>22^{\circ} \mathrm{C}$ & 5.2 & 4 \\
\hline $\mathrm{Cfb}$ & Moderate sea-climate, average temperature hottest month $<22^{\circ} \mathrm{C}$ & 6 & 10 \\
\hline $\mathrm{Cfc}$ & Cold sea-climate, max 4 months/year have an average temperature $>10^{\circ} \mathrm{C}$ & - & 6 \\
\hline Csa & Warm mediterranean-climate, average temperature hottest month $>22^{\circ} \mathrm{C}$ & 6.0 & 4 \\
\hline Csb & Moderate mediterranean-climate, average temperature hottest month $<22^{\circ} \mathrm{C}$ & 6 & 10 \\
\hline Csc & Cold mediterranean-climate, $\max 4$ months/year have an average temperature $>10^{\circ} \mathrm{C}$ & - & 6 \\
\hline Cwa & Warm China-climate, average temperature hottest moth $>22^{\circ} \mathrm{C}$ & - & 4 \\
\hline Cwb & Moderate China-climate, average temperature hottest moth $<22^{\circ} \mathrm{C}$ & - & 10 \\
\hline Cwc & Cold China-climate, max 4 months/year have an average temperature $>10^{\circ} \mathrm{C}$ & - & 6 \\
\hline \multicolumn{4}{|c|}{ GROUP D: Continental/microthermal climates } \\
\hline Dfa & Warm continental climate, average temperature hottest month $>22^{\circ} \mathrm{C}$ & 4 & 4 \\
\hline $\mathrm{Dfb}$ & Moderate continental climate, average temperature hottest month $<22^{\circ} \mathrm{C}$ & 5 & 10 \\
\hline Dfc & Cool continental climate, max 4 months/year have an average temperature $>10^{\circ} \mathrm{C}$ & - & 6 \\
\hline Dfd & Cold subartic continental climate, average temperature Coldest month $<-38^{\circ} \mathrm{C}$ & - & 2 \\
\hline Dsa & Warm mediterranean continental climate, average temperature hottest month $>22^{\circ} \mathrm{C}$ & - & 4 \\
\hline Dsb & Moderate mediterranean continental climate, average temperature hottest month $<22^{\circ} \mathrm{C}$ & - & 10 \\
\hline Dsc & Cool continental climate, max 4 months/year have an average temperature $>10^{\circ} \mathrm{C}$ & - & 6 \\
\hline Dsd & Cold subartic continental climate, average temperature Coldest month $<-38 \mathrm{C}$ & - & 2 \\
\hline Dwa & Warm continental climate, average temperature hottest month $>22^{\circ} \mathrm{C}$ & - & 4 \\
\hline Dwb & Moderate continental climate, average temperature hottest month $<22^{\circ} \mathrm{C}$ & - & 10 \\
\hline Dwc & Cool subartic continental climate, max 4 months/year have an average temperature $>10^{\circ} \mathrm{C}$ & 3.3 & 6 \\
\hline Dwd & Cold subartic continental climate, average temperature Coldest month $<-38^{\circ} \mathrm{C}$ & - & 2 \\
\hline \multicolumn{4}{|c|}{ GROUP E: Polar and Alpine climates } \\
\hline $\mathrm{EF}$ & Tundra climate $0{ }^{\circ} \mathrm{C} \leq \operatorname{Tmax}<+10{ }^{\circ} \mathrm{C}$ & 2 & 2 \\
\hline ET & Frost climate Tmax $<0$ & 2 & 2 \\
\hline
\end{tabular}




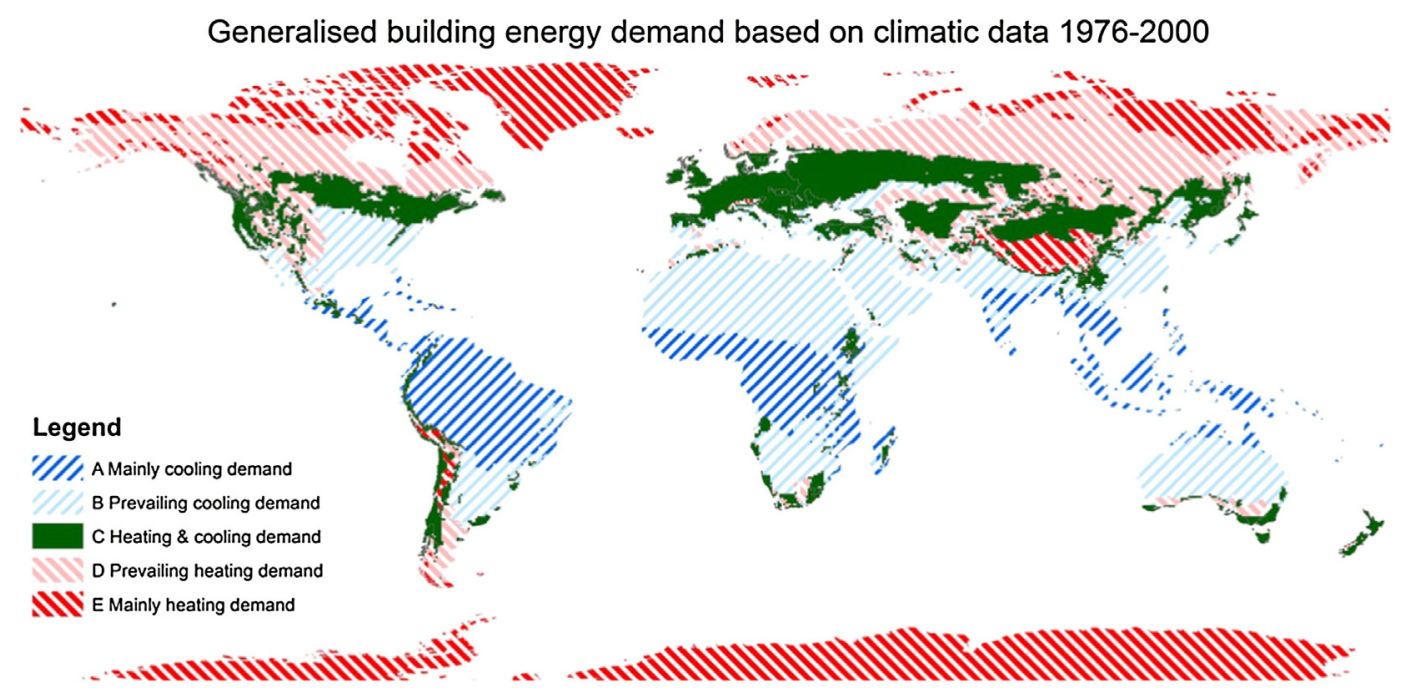

Fig. 7. Dominating demand for space heating and cooling, observation 1976-2000.

installed in buildings that obey high insulation standards (Aebischer et al., 2007; Bloemendal et al., 2014; Jelle et al., 2010). Aebischer et al. (Aebischer et al., 2007) show that the demand for cooling grows strongly, while that for heating decreases only little. Highquality insulation of buildings combined with the internal heat load causes cooling demand to become more dominant in the energy balance of modern buildings. This results in the fact that in climates with a longer and colder winter period, more buildings may have a balance in heating and cooling demand, and thus can successfully apply ATES, contrary to buildings in climates where summers are longer and warmer and, therefore, the cooling demand will dominate the energy balance.

- Every building has redundancy in its heating and cooling facilities to deal with imbalances and disturbances in energy demand and supply. An imbalance in heating and cooling demand larger than the ATES system can handle must be overcome with an additional regeneration facility, for instance by withdrawal of thermal energy from surface water or discharging surplus thermal energy into surface water, or by road heat exchangers or by exchanging heat with outside air.

- The temperature threshold between heating and cooling demand is around $18{ }^{\circ} \mathrm{C}$ with a bandwidth of $5{ }^{\circ} \mathrm{C}$ and a temperature difference of at least $5^{\circ} \mathrm{C}$ between the warmest and coldest month.
- Our description of the ATES suitability of climate classes was based on the required balance between yearly heating and cooling demand to be supplied by the subsurface. The size of the associated buildings was not taken into account.

\subsection{Climatic data translated to ATES suitability (II: comparing, IV: validating)}

The assumptions adopted in the previous section allow us to translate climatic properties to ATES suitability. The climate classifications of Koeppen-Geiger were divided into 5 ATES suitability classes as shown in Table 3.

A. Mainly cooling demand. This is the least favorable situation because it is then not possible to store the required cooling energy by lack of a sufficiently cold season.

B. Prevailing cooling demand. In this temperature range, ATES might be applicable (Ghaebi et al., 2014), but most of the buildings will have difficulties to store the required cooling capacity during the colder period.

C. Heating and cooling demand. In the regions with distinctive warm and cold seasons, heating and cooling demand will more or less balance, creating the most favorable conditions for ATES.

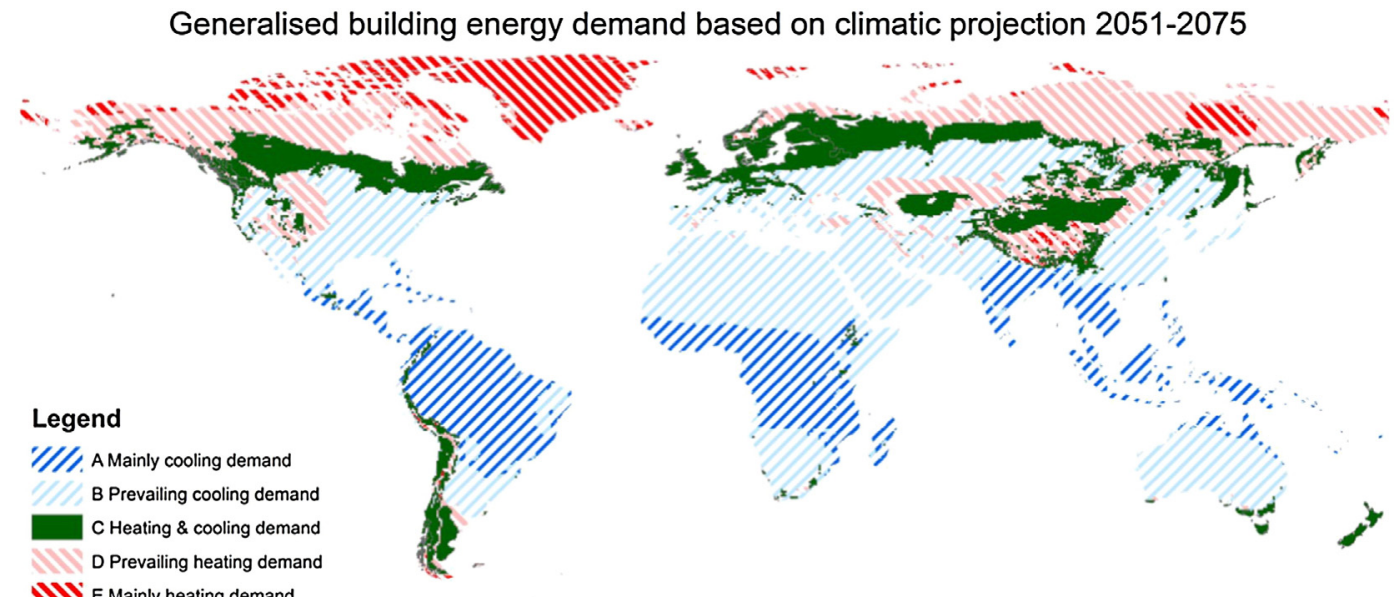

NW E Mainly heating demand 


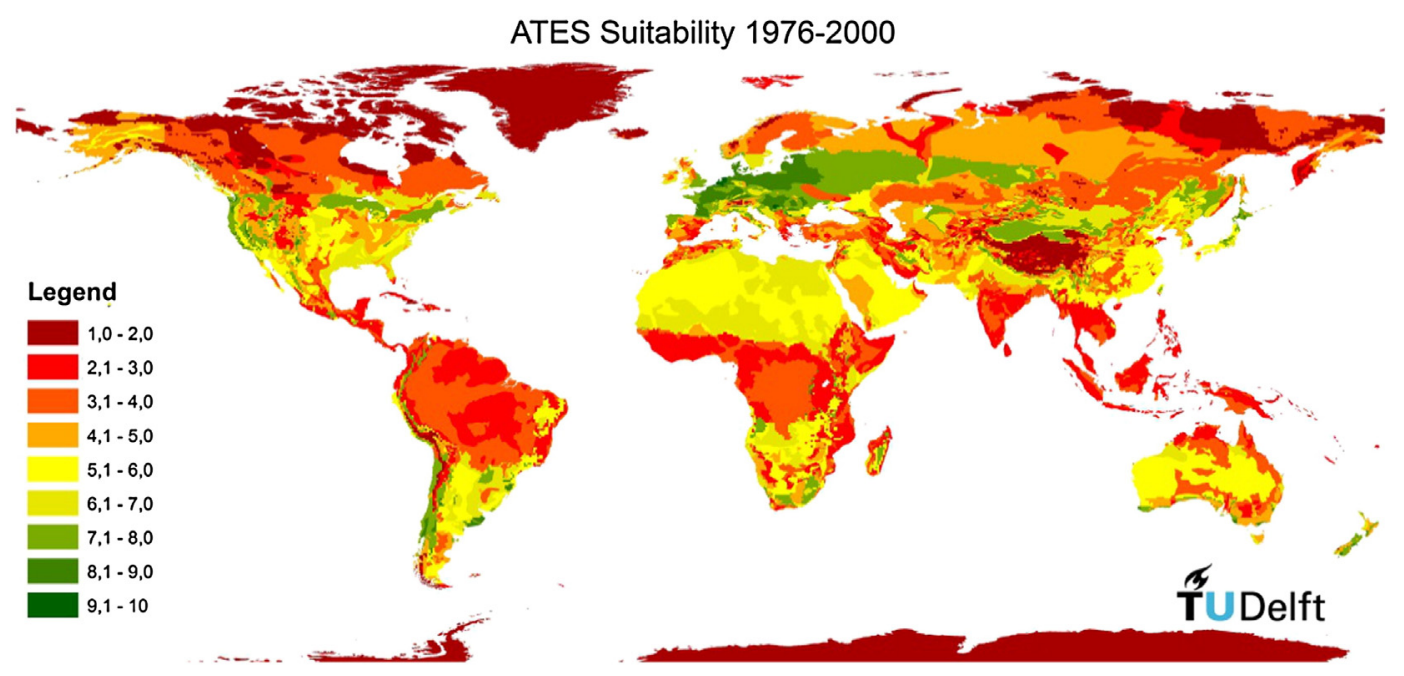

Fig. 9. ATES suitability 1976-2000.

D. Prevailing heating demand. Based on the fact that insulation of buildings will improve and the fact that internal heat loads in buildings will grow, these regions may become more suitable for ATES systems; this is a consequence of the rising temperature under climate change, since the average heating and cooling demand will better balance in the future (Bloemendal, 2012; Isaac and Vuuren, 2009). Therefore, suitability is better than type $\mathrm{B}$, with prevailing cooling demand.

E. Mainly heating demand. In this climate, it is not possible to store the required heat by lack of sufficiently warm summers; because of the same reason with climate types D and $B$, suitability was scored a little better than type A climate.

Based on these general properties, the ATES suitability scores defined above were associated with each climate class. The climatic descriptions and attributed ATES suitability's are given in Table 4. The ATES suitability classes resulting from the validation in step IV are also given in Table 4; for the validation step, the temperature intervals given in Table 3 were used. Only for the 'BWk' and 'Dfb' climate classes deviated the suitability scores considerably from the validation data. The other classes match well; the results generally confirm the suitability scores that were chosen to properly take into account climatic data for this classification.

\subsection{Results and discussion for ATES suitability based on climate conditions ( $V$ : processing)}

Rubel and Kottek (Rubel and Kottek, 2010) used several socioeconomic scenarios to make projections for the Koeppen-Geiger climate classification towards the end of the 21st century. In this paper, two different scenarios were used to classify ATES suitability: the classification based on observations of climate characteristics between 1976 and 2000 (Fig. 7), and the A1Fl-projection ${ }^{4}$ for the period 2051-2075 (Fig. 8) from Rubel and Kottek (Rubel and Kottek, 2010).

Fig. 7 shows that the area with climate conditions suitable for ATES is limited and mainly concentrated in the Eurasian and North American continent. The light-blue areas indicate where ATES can be used for buildings with a relatively low cooling or high heating demand, as the pink areas do for a relatively high cooling and high heating demand. Fig. 8 shows that in the second half of the 21st century, the suitable regions for ATES shift to the North and shrink. Only in southern Chili and Argentina the climatic conditions for ATES improve.

\footnotetext{
${ }^{4}$ IPCC Tyndall SC2.03 scenario [40].
}

The classification in this paper was based on general information on climate properties and was checked with observation data of a limited number climate classes. It might strengthen the reliability of the proposed ATES climate classification when more observed field data were used to validate the classification standard. Despite the limited scope of the validation, the obtained map indicates which regions may be suitable for applying ATES technology that also match regions with known ATES application.

The ratio between heating and cooling demand was generalized for buildings. In any climatic region, cases with an unexpected energy demand may occur.

In the climate classification of Koeppen-Geiger (Kottek et al., 2006), the size of the geographical unit appointed to a certain climate varies from the size of half a continent such as North-Western Europe and Siberia, to that of one grid-cell of $0.5^{\circ} \times 0.5^{\circ}$. As a result, in some coastal and mountainous areas, climate classes vary a lot over a short range, while in practice ATES applicability does not differ much over a $0.5^{\circ}$ distance. This ambiguity supports the approach of lumping the 31 original climate classes into 5 ATES suitability classes and the distinction that was made between areas with mainly cooling and mainly heating demand. So climate types B and D are likely to be more suitable when they are located close to type $C$ climates, and less suitable when they are close to climate types $\mathrm{A}$ or $\mathrm{E}$.

A way to improve the results, is to distinguish between different types of buildings and energy demand profiles that depend on climatic conditions. However, this would make the validation process more laborious and more difficult to understand and explain. Therefore, it was chosen not to follow that path in this paper, but it may be a route to follow in further detailing this map.

It is still uncertain to what extent the projected climate classification will be effective in reality. So the results of this study should be updated periodically, with recent climate data and new projections.

\section{Results: potential for ATES}

\subsection{Combining geo-hydrological and climate suitability maps to obtain the world ATES suitability map}

To obtain our ATES suitability map, the obtained geo-hydrological and climatic suitability scores were combined in a GIS environment. Because we considered ATES suitability to be equally dependent on climatic and on geo-hydrologic conditions, we average the suitability scores in this operation $\left(S^{A T E S}=\left(S^{G E O}+S^{C l i m}\right) / 2\right)$. Only when either the geo- 


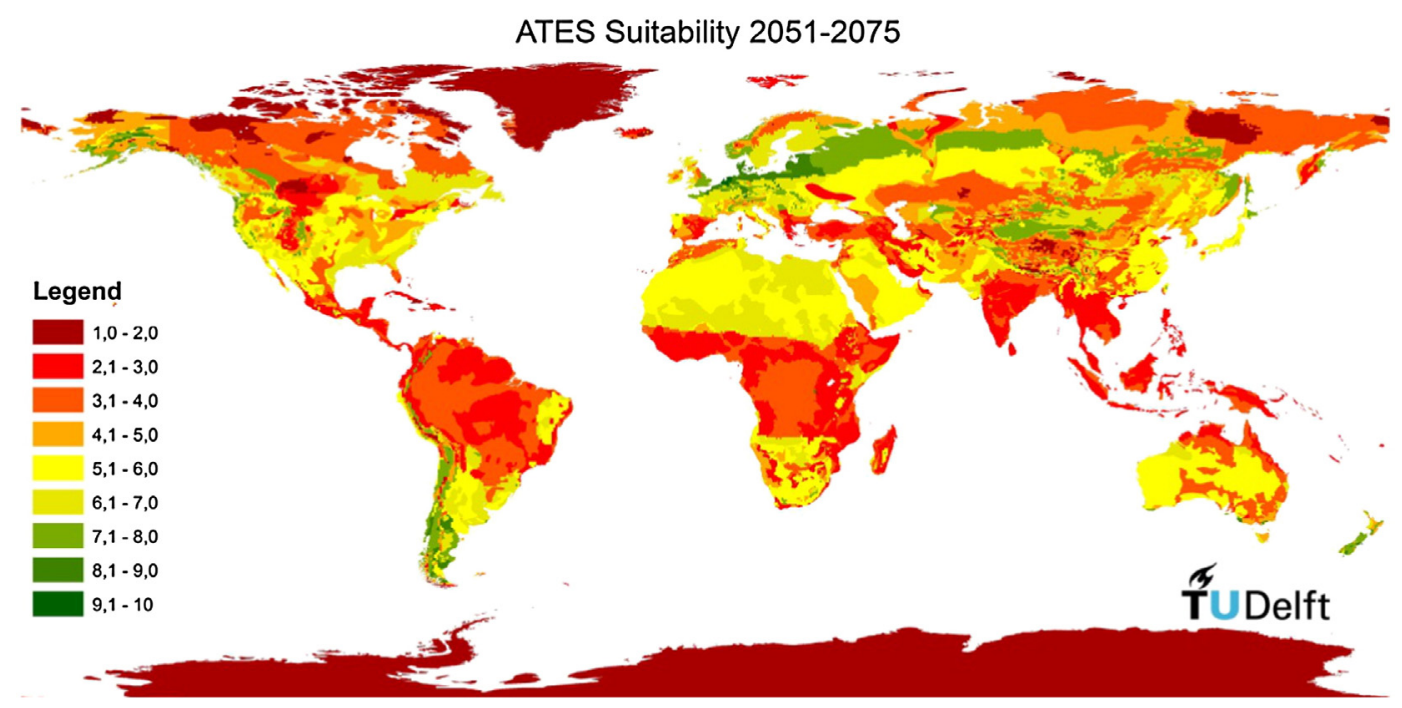

Fig. 10. ATES suitability projection 2051-2075.

hydrological or the climatic suitability score was low (i.e. less than 3 ), this score is considered to be decisive for the applicability. For instance, a building with a perfect energy balance will not adopt ATES in an area unsuitable to make groundwater wells. So when a suitability score is lower than 3 in either map, it will be weighted 3 times $^{5}$ in the averaging, preventing the final map to contain many areas of middle-range suitability that in practice have no suitability at all. Fig. 9 shows the ATES suitability based on 1967-2000 climate observations; the ATES suitability for the climate projection of 2051-2075 is shown in Fig. 10. As can be seen, there will be very suitable areas in Europe, Asia and NorthAmerica, but also in other continents several smaller isolated areas will be suitable for the applying of ATES systems.

\subsection{Using urban population data to identify ATES hot-spots}

The urbanization data used consists of historic population numbers and the population projections for 588 urbanized areas spread over the world (Ahlenius, 2014; United Nations, 2008). The percentages of urban population living in areas of different ATES potential are given in Table 5. The data used does not include all urban areas in the world, however the percentages derived from the maps are representative indicators for the world urban population. At the end of the 20th century, $15 \%$ of the world's urban population lives areas with a high suitability for ATES application. This percentage will drop to about 3\% in 2051-2075 as a result of climate change. As a consequence of urbanization, the total number of people living in high potential areas will decrease by $50 \%$ with respect to the situation in 2000 .

The urban population living in the medium ATES suitability range will be constant, around 50\%; the climatic zones shift for these areas, the total fraction of the urban population however, remains more or less constant. Because of increasing urbanization, the number of people living in medium ATES suitability areas will increase by $140 \%$. For these people, ATES applicability depends on local climate, geo-hydrological and building conditions.

About $30 \%$, and later $50 \%$ of the population living in urban areas does not have the opportunity to efficiently apply ATES.

Where climate conditions are favorable and geo-hydrological conditions are medium to good, mutual interference between adjacent ATES systems is likely to occur because demand for ATES is most likely to exceed availability of subsurface space in these areas, which results in scarcity of subsurface space for accommodation and further

\footnotetext{
5 The factor was chosen to be 3 , to make sure that in the biggest difference in suitability's (10 and 1 ) would result in a total suitability of 3 (rounded).
}

development of ATES (Bloemendal et al., 2014). Therefore, it was analyzed where climate conditions are best (scores 6 and 10), and geological conditions are medium and good (scores in the range 4-10). This analysis showed that in the second half of the 21 st century $44 \%$ of the urban population will live in areas where scarcity of space in the subsurface may become an issue. As can be seen in Fig. 11, most cities where lack of subsurface space is likely to occur lie in North America, Europe and mainly Asia.

\section{Conclusions and discussion}

The ATES suitability maps constructed and presented in this paper, were composed of freely available information and datasets. The actual suitability for the application of ATES systems in practice may deviate from results in presented maps due to differences with local subsurface conditions or deviating energy demand of buildings. The method used to establish the potential maps was proposed in this paper and was validated using local and detailed information from regions where ATES is already applied. Application of the method gave the insight in; where ATES should be applicable, but where it is not yet applied, like in Russia and in parts of Asia and in southern South America. It also showed that ATES will become applicable in other parts of northern North America and Russia during the second half of the 21st century. The combination with urbanization data showed which part of the urban world population lives in areas with a suitable aquifer and climate and where demand for ATES may exceed available subsurface space. In these areas, legislation may need substantiation to allow for sustainable and optimal use of the subsurface for ATES.

In some cases, the suitability derived from the two geo-hydrological data sets did not agree as was discussed in Section 2.4. This is partly caused by differences in the scales of spatial reference and limited availability of some data subsets. Improvement of the geo-hydrological ATES suitability maps should best focus on detailing larger countries and the collecting more data from developing countries. Nevertheless, we

Table 5

Potential for ATES as a percentage of urban population.

\begin{tabular}{|c|c|c|c|c|c|c|c|c|c|}
\hline \multirow[t]{2}{*}{ ATES potential } & \multicolumn{3}{|c|}{ Poor } & \multicolumn{3}{|c|}{ Medium } & \multicolumn{3}{|c|}{ Good } \\
\hline & $1-2$ & $2-3$ & $3-4$ & $4-5$ & $5-6$ & $6-7$ & $7-8$ & $8-9$ & $9-10$ \\
\hline $1976-2000$ & $\begin{array}{l}0 \% \\
31 \%\end{array}$ & $13 \%$ & $18 \%$ & $\begin{array}{l}9 \% \\
54 \%\end{array}$ & $23 \%$ & $21 \%$ & $\begin{array}{l}10 \% \\
15 \%\end{array}$ & $5 \%$ & $0 \%$ \\
\hline 2051-2075 & $\begin{array}{l}0 \% \\
47 \%\end{array}$ & $22 \%$ & $25 \%$ & $\begin{array}{l}7 \% \\
50 \%\end{array}$ & $29 \%$ & $14 \%$ & $\begin{array}{l}2 \% \\
3 \%\end{array}$ & $1 \%$ & $0 \%$ \\
\hline
\end{tabular}




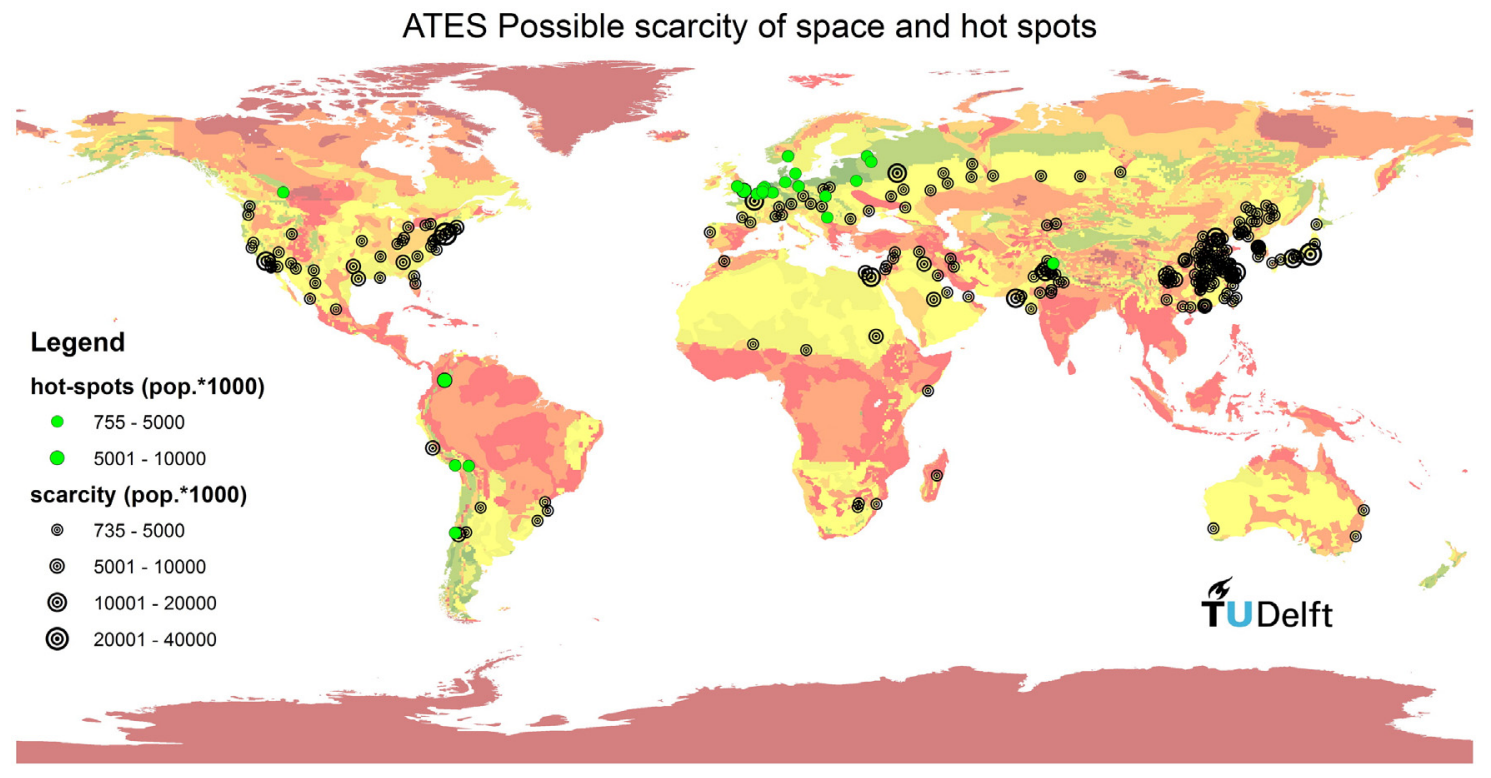

Fig. 11. Urban areas with ATES hot-spot \& possible scarcity of space (2051-2075).

showed that for $75 \%$ of the validated areas the results were in agreement, indicating that after validation the defined geo-hydrological suitability is a good representation of the expected suitability for ATES that was based on detailed information of a number of selected countries.

The climatic suitability was determined in a straightforwardly by lumping all types of buildings, building use and insulation standards to a single energy-demand pattern albeit with a large bandwidth. Considering the fact that the climatic dataset has a relative large (50\%) influence on the final suitability score, a more sophisticated approach would be justified. For instance, A) validating the seasonal patterns and average temperature values of the climate-class descriptions with more data from different climate classes and B) evaluate how the ATES suitability of different types of buildings and/or insulation standards differ. Despite the limitations underlying the determination of climatic ATES suitability, this simple but well substantiated approach was shown to give the required insight in ATES suitability and allows concluding what to expect for in most regions.

\section{Acknowledgments}

This research was supported by Climate-kic E-use (aq) and the URSES research program funded by the Dutch organization for scientific research (NWO: 408-13-030) and Shell. We also thank three anonymous reviewers for their valuable comments, contributing to the quality of this final paper.

\section{References}

Aebischer, B., Catenazzi, G., Jakob, M., 2007. Impact of Climate Change on Thermal Comfort, Heating and Cooling Energy Demand in Europe, Summer Study Saving Energy. ECEE.

Ahlenius, H., 2014. Projections of Population Living in Urbanized Areas. In: Ahlenius, H. (Ed.).

Beek, C.G.E.M.v., 2010. Cause and Prevention of Clogging of Wells Abstracting Groundwater from Unconsolidated Aquifers, Geo-sciences. VU-Amsterdam, Amsterdam.

Bertani, R., 2005. World Geothermal Generation 2001-2005: State of the Art. World Geothermal Congress Antalya, Turkey.

BGR, UNESCO, 2008. IGRAC Groundwater Resources of the World. In: IGRAC (Ed.)IGRAC, Hannover, Germany.

Bloemendal, M., 2010. Groundwater Databases of Dutch Provinces. Received from the 12 Provinces of the Netherlands in 2010.

Bloemendal, M., 2012. Klimaatscenario's en balans van WKO-systemen (influence of climate change on ATES systems). TAUW, Rotterdam.

Bloemendal, M., Olsthoorn, T., Boons, F., 2014. How to achieve optimal and sustainable use of the subsurface for Aquifer Thermal Energy Storage. Energy Policy 66, 104-114.
Blum, P., Campillo, G., Munch, W., Kolbel, T., 2010. CO2 saving of ground source heat pump systems - a regional analysis. Renew. Energy 35, 122-127.

Bonte, M., 2013. Impacts of Shallow Geothermal Energy on Groundwater Quality, Geo Sciences. Vrije Universiteit Amsterdam, Amsterdam.

Caljé, R., 2010. Future use of Aquifer Thermal Energy Storage in Below the Historic Centre of Amsterdam, Hydrology. Delft University of Technology, Delft.

Chen, H., 2014. Köppen Climate Classification as a Diagnostic Tool to Quantify Climate. In: Chen, H., Chen, D. (Eds.), University, P.S. (retrieved from: http://hanschen.org/ koppen/ September 2014).

Delfland, W.o., 2010. Leidraad regulering grondwateronttrekkingen en infiltraties, Regulations for abstracting and infiltrating groundwater. In: Delfland, W.o. (Ed.) (Delft).

Eugster, W.J., Sanner, B., 2007. Technological status of shallow geothermal energy in Europe. European geothermal congress, Unterhaching, Germany.

EU-Parliament, 2010. Directive on the Energy Performance of Buildings. In: Official Journal of the European Union (Ed.) 153. European Union, Strasbourg, pp. 13-35.

Ferretti, V., 2011. A multicriteria spatial decision support system development for siting a landfill in the province of Torino (Italy). J. Multi-Criteria Decis. Anal. 18, 231-252.

Fry, V.A., 2009. Lessons from London: regulation of open-loop ground source heat pumps in central London. Geol. Soc. Lond. 42, 325-334.

Geo.Power, 2012. Regional Strategies for the Large Scale Introduction of Geothermal Energy in Buildings.

Ghaebi, H., Bahadori, M.N., Saidi, M.H., 2014. Performance analysis and parametric study of thermal energy storage in an aquifer coupled with a heat pump and solar collectors, for a residential complex in Tehran, Iran. Appl. Therm. Eng. 62, 156-170.

Ground-reach, 2007. Market Status for Ground Source Heat Pumps in Europe.

Haehnlein, S., Bayer, P., Blum, P., 2010. International legal status of the use of shallow geothermal energy. Renew. Sust. Energ. Rev. 14, 2611-2625.

Hoekstra, N., Slenders, H., van de Mark, Smit, M., Bloemendal, M., Van de Ven, F., Andreu, A., Sani, D., Simmons, N., 2015. Europe-wide Use of Sustainable Energy from Aquifers, Complete report. Climate-KIC (in press).

Isaac, M., Vuuren, D.P.v., 2009. Modeling global residential sector energy demand for heating and air conditioning in the context of climate change. Energy Policy 37, 507-521.

Jelle, B.P., Gustavsen, A., Baetens, R., 2010. The high performance thermal building insulation materials and solutions of tomorrow. ASHRAE Buildings conference XI.

Jerven, M., 2013. Poor numbers: How We are Misled by African Development Statistics and What to Do about It. Cornell University Press, Ithaca.

Karrenberg, H., 1976. International Hydrogeological Map of Europe. UNESCO.

Kottek, M., Grieser, J., Beck, C., Rudolf, B., Rubel, F., 2006. World map of the Köppen-Geiger climate classification updated. Meteorol. Z. 15, 259-263.

Lund, J.W., Freeston, D.H., 2001. World-wide direct uses of geothermal energy 2000. Geothermics 30, 29-68.

Lund, J., Sanner, B., Rybach, L., 2004. Geothermal (ground source) heat pumps, a world overview. Geo-Heat Centre Q. Bull. 1-10.

Lund, J.W., Freeston, D.H., Boyda, T.L., 2011. Direct utilization of geothermal energy 2010 worldwide review. Geothermics 40, 159-180.

Malczewski, J., 1999. GIS and Mulitcriteria Decision Analysis. John Wiley \& Sons, New York.

Malczewski, J., 2006. GIS-based multicriteria decision analysis: a survey of the literature. Int. J. Geogr. Inf. Sci. 20, 703-726.

NVOE, 2006. Richtlijnen Ondergrondse Energieopslag, Design Guidelines of Dutch Branche Association for Geothermal Energy Storage (Woerden).

Pidwirny, M., 2011. Köppen Climate Classification System, retrieved from: http://www eoearth.org/view/article/162263 (September 2014). 
Richts, A., Struckmeier, W.F., Zaepke, M., 2011. WHYMAP and the Groundwater Resources of the World. In: Jones, J.A.A. (Ed.), WHYMAP.

Rubel, F., Kottek, M., 2010. Observed and projected climate shifts 1901-2100 depicted by world maps of the Köppen-Geiger climate classification. Meteorol. Z. 19, 135-141.

SER, Energie Akkoord, 2013. Social Economical Counsil of NL (Ed.).

Sommer, W., 2015. Modelling and Monitoring Aquifer Thermal Energy Storage. Wageningen University, Wageningen.

Sommer, W., Valstar, J., van Gaans, P., Grotenhuis, T., Rijnaarts, H., 2013. The impact of aquifer heterogeneity on the performance of aquifer thermal energy storage. Water Resour. Res. 49, 8128-8138.

Sommer, W., Valstar, J., Leusbrock, I., Grotenhuis, T., Rijnaarts, H., 2015. Optimization and spatial pattern of large-scale aquifer thermal energy storage. Appl. Energy 137, 322-337.

United Nations, D, 2008. World Population Prospect 2008. In: Affairs, U.D.o.E.a.S. (Ed.).
Verbong, G., van Selm, A., Knoppers, R., Raven, R.P.J.M., 2001. Een Kwestie van Lange Adem. De Geschiedenis van Duurzame Energie in Nederland 1970-2000. Aeneas, Boxtel.

Vetmed uni Vienna, I.f.V.P.H., 2014. World maps of Koeppen-Geiger Climate Classification, retrieved from: http://koeppen-geiger.vu-wien.ac.at/ (September 2014).

Yang, W., Zhou, J., Xu, W., Zhang, G., 2010. Current status of ground-source heat pumps in China. Energy Policy 38, 323-332.

Zuurbier, K.G. Hartog N. Valstar, J. Post, VE, van Breukelen, B.M, 2013. The impact of low-temperature seasonal aquifer thermal energy storage (SATES) systems on chlorinated solvent contaminated groundwater: modeling of spreading and degradation. J. Contam. Hydrol. 147, 1-13. 